\title{
Insight into the combined colloidal-humic acid fouling on the hybrid coagulation microfiltration membrane process: The importance of aluminum
}

\author{
Ping Xiao ${ }^{\mathrm{a}, \mathrm{b}}$, Feng Xiao ${ }^{\mathrm{b}, *}$, Weijun Zhang ${ }^{\mathrm{b}}$, Bingqing Zhao ${ }^{\mathrm{b}}$, Dongsheng Wang ${ }^{\mathrm{b}, *}$ \\ a Center of Membrane Technology and Application Engineering, Key Laboratory of Reservoir Aquatic Environment, Chongqing Institute of Green and \\ Intelligent Technology, Chinese Academy of Sciences, 266 Fangzheng Avenue, Shuitu Hi-tech Industrial Park, Shuitu Town, Beibei District, Chongqing \\ 400714, China \\ ${ }^{\mathrm{b}}$ State Key Laboratory of Environmental Aquatic Chemistry, Research Center for Eco-Environmental Sciences, Chinese Academy of Sciences, 18 Shuangqing \\ Road, Beijing 100085, China
}

\section{H I G H L I G H T S}

- Fouling behavior of HA and kaolin is studied in coagulation-microfiltration process.

- Coexistence of HA and kaolin displayed an apparent synergic fouling effect.

- Different mechanisms governed the fouling process with increase in aluminum dosage.

- Properties of flocs rather than cake layer mass decided the membrane performance.

\section{A R T I C L E I N F O}

\section{Article history:}

Received 21 May 2014

Received in revised form 17 July 2014

Accepted 21 July 2014

Available online 30 July 2014

\section{Keywords:}

Aluminum

Combined colloid-organic

Membrane fouling

Microfiltration

\section{G R A P H I C A L A B S T R A C T}

\begin{abstract}
A B S T R A C T
The hybrid coagulation-microfiltration process has been used for water treatment plants. However, membrane fouling is still the major barrier for its application. In this study, the impact of interactions between natural organic matter and particles on fouling has been investigated. The model substances were kaolin, humic acid and aluminum as the coagulant. The results demonstrated that flux was almost kept constant for humic acid due to its linear structure. However, the flux of the synthetic solution decline was substantial. More interesting, the addition of aluminum with different dosages played a significant role in membrane filtration. With the low dosage of $\mathrm{AlCl}_{3}$ as $0.06 \mathrm{mmol} / \mathrm{L}$, there were no visible flocs, but the flux of the synthetic solution showed a noticeable decreasing due to the complexation of humic acid and aluminum. With the increase of aluminum, the flux was apparently improved for the flocs formed. It indicated that the dosage of coagulant was a key parameter to decide the effect of filtration since coagulation had both positive and negative effects on membrane fouling. Additionally, the experimental results also revealed that the floc structure and pore blocking might take the major responsibility for the flux decline.
\end{abstract}

(C) 2014 Elsevier B.V. All rights reserved.

\footnotetext{
* Corresponding authors. Tel.: +86 10 62849138; fax: +86 1062849138.

E-mail addresses: fengxiao@rcees.ac.cn (F. Xiao),wgds@rcees.ac.cn (D. Wang).
}

\section{Introduction}

Membrane filtration has been widely used for water and waste water treatment in the past decade [1-3]. Particularly, the hybrid coagulation-microfiltration process which does not require 
settling processes are becomes more and more popular in China due to various reasons, such as the strict regulatory requirements for the effluent quality, operation easiness, limited footprints and competitive cost [4-8]. However, membrane fouling which can cause serious flux decline is still a major barrier limiting its wide application. Particles, organic matters and inorganic ions are identified to cause membrane fouling with various mechanisms. Almost all studies on the membrane fouling in water treatment have focused on single type foulant, either colloidal foulants or organic foulants [9-11].

Natural organic matters (NOMs) consisting of a variety of biorefractory organic compounds including humic substances have been widely reported as the major foulant during surface water filtration [12-14]. And NOMs usually can combine with particles in the aqueous environment [15]. This occurrence modified the physicochemical characteristics of the colloidal-NOMs surface. Previous research suggested that NOMs especially humic substances could improve the stability of particle suspension, and that divalent cations would destabilize them [16,17]. More recently, some specific fractions of NOMs were found to be effectively destabilized in the presence of particles [18].

Over the past few decades, coagulation/flocculation was widely used as a pretreatment step of microfiltration and ultrafiltration for water treatment [6,19-21]. Kim et al. [22] suggested that coagulation can improve the membrane flux and mitigate fouling by changing particle characteristics at low aluminum dosage and reducing the foulants loading at high aluminum dosage. Wang et al. [23] found that both structure and size of aggregates played important roles in membrane filtration by investigating the effects of particle charge, size and fractal dimension under different pre-coagulation $\mathrm{pH}$ and aluminum dosages on microfiltration (MF) membrane performance. Although the coagulation pretreatment has several advantages, some studies have demonstrated that it also could aggravate membrane fouling by serious pore blockage. Carroll et al. [24] reported the fouling became more serious caused by NOM after coagulation treatment. Schäfer et al. [25] found membrane flux experienced a noticeable declining during the flat microfiltration process, when used ferrous salts as the coagulants. A similar phenomenon was found for the UF membrane. Judd and Hillis [26] indicated that the flocs should come to a certain size; otherwise the flocs would block membrane pores and cause irreversible fouling. Other researches [27] also reported the addition of coagulants aggravated fouling in coagulation-membrane filtration process. Researches on combined fouling of NOM-particle on membrane filtration process have been published in the past few decades [18,28,29]. These contradictory results might be attributed to the fact that the mutual interaction among colloidal-NOM has important effect on membrane fouling. Nevertheless, combined NOM-particle fouling on hybrid coagulation-MF membrane process still needs further understanding. However, knowledge of such combined effects could be vital to better understanding of membrane fouling and has a great practical impact in the industrial applications.

The objective of the present work is to seek a further understanding of the fouling mechanism of NOM combined with colloidal particles with the addition of the coagulant $\left(\mathrm{AlCl}_{3}\right)$ in the hybrid coagulation-MF membrane process. Experiments were designed to: (1) compare the extent of flux decline under different solution with or without coagulant; (2) understand the interaction of NOMs, inorganic particles and coagulant, as well as their combined influence on membrane performance and fouling.

\section{Materials and methods}

\subsection{Model foulants}

Kaolin (Aldrich, Milwaukee, WI) was applied as a model particle. The stock suspension of kaolin was prepared with deionized water.
Table 1

Characteristics of the model waters.

\begin{tabular}{llll}
\hline Model water & $\begin{array}{l}\text { Dosage of } \\
\mathrm{AlCl}_{3} \\
(\mathrm{mmol} / \mathrm{L})\end{array}$ & Particle state & $\begin{array}{l}\text { Permeate } \\
\mathrm{UV}_{254}\left(\mathrm{~cm}^{-1}\right)\end{array}$ \\
\hline HA, 3 mg-C/L & 0 & - & 0.375 \\
Kaolin, 50 mg/L & 0 & Suspension & - \\
Kaolin, 50 mg/L-HA, 3 mg-C/L & 0 & Suspension & 0.294 \\
Kaolin, 50 mg/L-HA, 3 mg-C/L & 0.12 & Aggregation & 0.015 \\
HA, 3 mg-C/L & 0.06 & Stable & 0.026 \\
Kaolin, 50 mg/L-HA, 3 mg-C/L & 0.06 & Suspension & 0.023 \\
HA, 3 mg-C/L & 0.16 & Aggregation & 0.007 \\
Kaolin, 50 mg/L-HA, 3 mg-C/L & 0.16 & Aggregation & 0.012 \\
\hline
\end{tabular}

The solid concentration of suspension was determined gravimetrically to be $33 \mathrm{mg} / \mathrm{L}$. The average size of particles in the suspension was close to $2.6 \mu \mathrm{m}$, measured by a laser diffraction instrument (Mastersizer 2000, Malvern, UK). The concentration of kaolin suspension was determined as $50 \mathrm{mg} / \mathrm{L}$.

The humic acid (HA) was selected to represent the natural organic matter. HA (Tianjin, China) stock solution was made by dissolving $4 \mathrm{~g}$ of HA into $500 \mathrm{~mL} 0.01 \mathrm{M} \mathrm{NaOH}$ solution. Then, the solution was stirred for $24 \mathrm{~h}$, and filtered through a $0.45 \mu \mathrm{m}$ membrane to remove residual non-dissolved humic acid. Dissolved organic carbon (DOC) was measured by a TOC analyzer (TOC-Vcph, Shimadzu, Japan). The concentration of HA solution was $3 \mathrm{mg}-\mathrm{C} / \mathrm{L}$.

\subsection{Synthetic waters and jar-test experiment}

The synthetic water was prepared by dissolving the HA stock solution and kaolin stock suspension in deionized water with $0.001 \mathrm{~mol} / \mathrm{L} \mathrm{NaHCO}_{3}$ to provide ionic strength and $\mathrm{pH}$ buffers. An aluminum chloride $\left(\mathrm{AlCl}_{3}\right.$, analytical grade, Beijing Chemical Regent Company, China) was added as the coagulant during the flocculation at room temperature $\left(\sim 22^{\circ} \mathrm{C}\right)$ on the synthetic waters with a jar-test device (ZR4-6, Zhongrun, Shenzhen, China). The jar-tester consisted of six 1-L rectangular beakers, each was filled with $500 \mathrm{~mL}$ water. The mixing was provided by flat paddle mixers $(5.0 \mathrm{~cm} \times 4.0 \mathrm{~cm})$. The concentration of the added $\mathrm{AlCl}_{3}$ was ranged from 0 to $0.16 \mathrm{mmol} / \mathrm{L}$.

For a jar-test run, the synthetic water was first mixed rapidly at $250 \mathrm{rpm}$ for $30 \mathrm{~s}$. Then the coagulant was added by pipettes at the beginning of a rapid mixing with $200 \mathrm{rpm}$ for $1 \mathrm{~min}$. Following the rapid mixing, the water in the jar-test beakers was mixed for flocculation at a slower rate of $40 \mathrm{rpm}$ for $15 \mathrm{~min}$. The floc sizes were evaluated using the laser particle analyzer (Mastersizer 2000, Malvern, UK) and dynamic laser light scattering instrument (BI200sm, Brookhaven Instruments Corporation, USA). After another 20 min for settling, the supernatant water was taken for water quality measurements. The turbidity of the waters was measured with a Turbidimeter (2100P, HACH, Loveland, USA), and UV $_{254}$ was measured by a spectrophotometer (UV-Vis 8500 , China) using a $1 \mathrm{~cm}$ quartz cell after filtration through $0.45 \mathrm{~mm}$ membrane. A summary of the eight synthetic water characteristics was shown in Table 1.

\subsection{Microfiltration procedure}

A schematic diagram of the MF system used in this study was shown in Fig. 1. Microfiltration began immediately at the end of coagulation and the suspension was stirred continuously with slow mixing intensity of $40 \mathrm{rpm}$ at the same time. The floc was sucked carefully into the membrane cell by a vacuum pump (GAST, USA) to avoid floc breakage. Membrane filtration experiments were conducted in a $50 \mathrm{~mL}$-capacity unstirred batch cell and operated in dead-end filtration. A feed reservoir with $2 \mathrm{~L}$ was connected to the stirred batch cell and each solution was transferred into the 


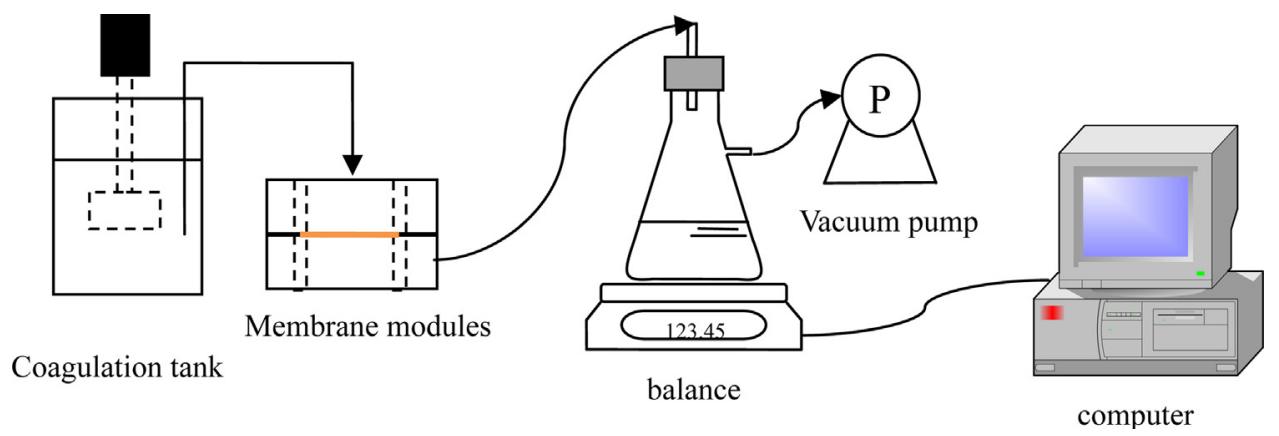

Fig. 1. Schematic experimental setup of the coagulation-microfiltration hybrid process.

feed reservoir and slowly agitated to make a uniform suspension. The flat sheet of MF (polyvinylidene fluoride, PVDF) membrane (DURAPORE ${ }^{\circledR}$ membrane filters, Millipore, USA) with an average pore size of $0.22 \mu \mathrm{m}$ was used in this study. The membrane was placed at the bottom of the cell with smooth side toward the bulk solution. Nitrogen gas at constant pressure of $50 \mathrm{kPa}$ was applied to drive the feed solution through membrane. Permeate mass was weighed by an electronic balance (PL2002-IC, Mettler-Toledo, Switzerland) and recorded via a personal computer equipped with a data acquisition system (Fig. 1). The filtration was terminated when the accumulated permeate volume reached $250 \mathrm{~mL}$. A new piece of membrane was used in all the experiments. The membrane was soaked in deionized water at least $24 \mathrm{~h}$ before use. The pure water flux was measured before each experiment.

\section{Results and discussion}

\subsection{Properties of model solutions}

Table 1 shows the properties of eight model solutions. It is observed that particles will aggregate with each other and form flocs if the addition of $\mathrm{AlCl}_{3}$ reached to $0.12 \mathrm{mmol} / \mathrm{L}$ and $0.16 \mathrm{mmol} / \mathrm{L}$, while the other five solutions are very stable. For HA permeate, the $U_{254}$ almost keeps the same which means that HA cannot be retained by MF filtration. The value of $U_{254}$ decreases a little to $0.294 \mathrm{~cm}^{-1}$ in the HA-kaolin synthetic solution compares to pure HA solution due to the absorption of HA on kaolin particles. Over $90 \%$ of $\mathrm{UV}_{254}$ is removed when $0.06 \mathrm{mmol} / \mathrm{L} \mathrm{AlCl}_{3}$ is added for both HA and HA-kaolin solutions. Furthermore, no visible flocs can be detected. With the increase of the $\mathrm{AlCl}_{3}$ from $0 \mathrm{mmol} / \mathrm{L}$ to $0.16 \mathrm{mmol} / \mathrm{L}$, the $\mathrm{UV}_{254}$ of $\mathrm{HA}$ solution can decrease from $0.375 \mathrm{~cm}^{-1}$ to $0.007 \mathrm{~cm}^{-1}$.

\subsection{Membrane performance}

The variation in MF permeate flux of HA solution, kaolin solution and HA-kaolin synthetic solution can be found in Fig. 2. It is interesting to note that the flux of HA solution is almost constant during the whole filtration process. According to the previous researches $[30,31]$, the structure of HA appears a flexible linear under a low concentration ( $3.0 \mathrm{mg}-\mathrm{C} / \mathrm{L}$ ) and a high $\mathrm{pH}(8)$, hence they can easily pass through membrane pores. Nevertheless, the membrane flux for both kaolin and HA-kaolin solutions decline sharply. The performance of the synthetic solution seems to be better than that of the kaolin solution since the flux of synthetic solution is a little bit higher at the end of filtration. It is considered that the adsorption of HA improved the surface negative charges of kaolin, leading to a higher electrostatic repulsion between particles and formation of looser cake layer on membrane surface. It could improve the porosity of the cake layer, resulting in a higher flux.

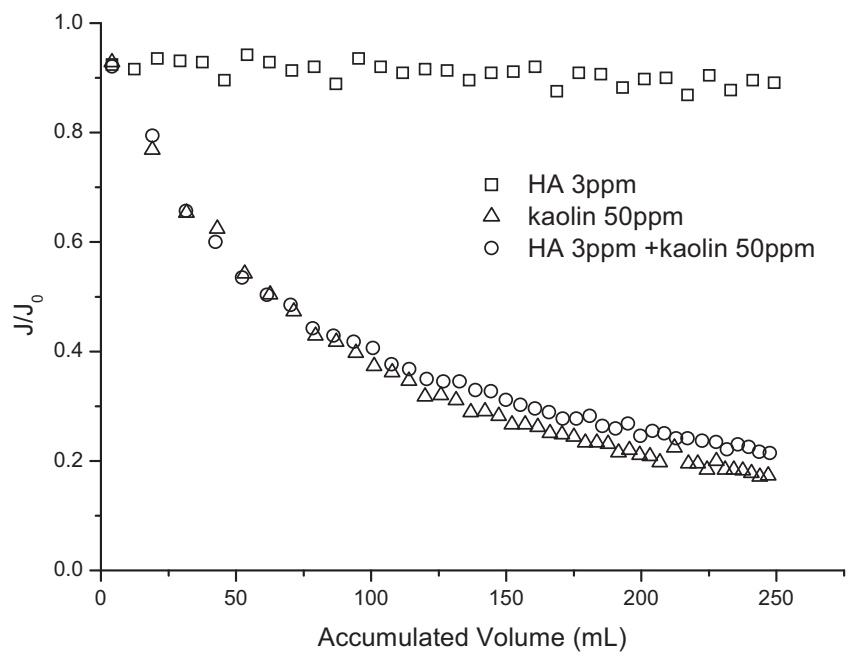

Fig. 2. Flux variations of different model solutions.

\subsection{Effect of colloidal particles}

Fig. 3 describes fouling behaviors with/without kaolin. It can be noticed that the difference of flux with/without kaolin is not obvious. Theoretically, the mass of the cake layer could have a big difference. It would have $50 \mathrm{mg}$ cake layer difference in per liter permeate. But this difference actually causes a little effect on membrane flux in the experiments. The results are very thoughtprovoking. For the systems with a higher aluminum addition, it can be explained that the resistance of the cake layer is mainly

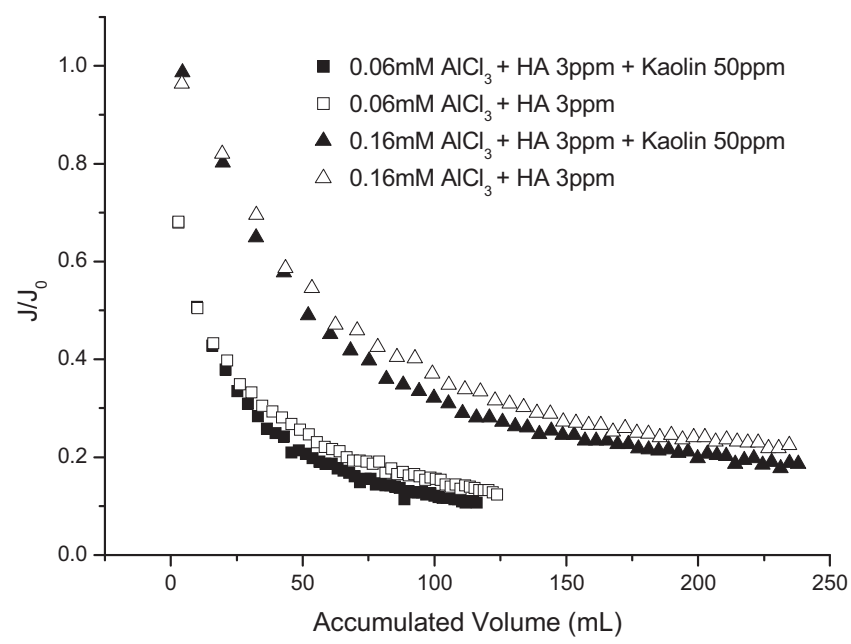

Fig. 3. Effects of kaolin colloids on membrane flux. 

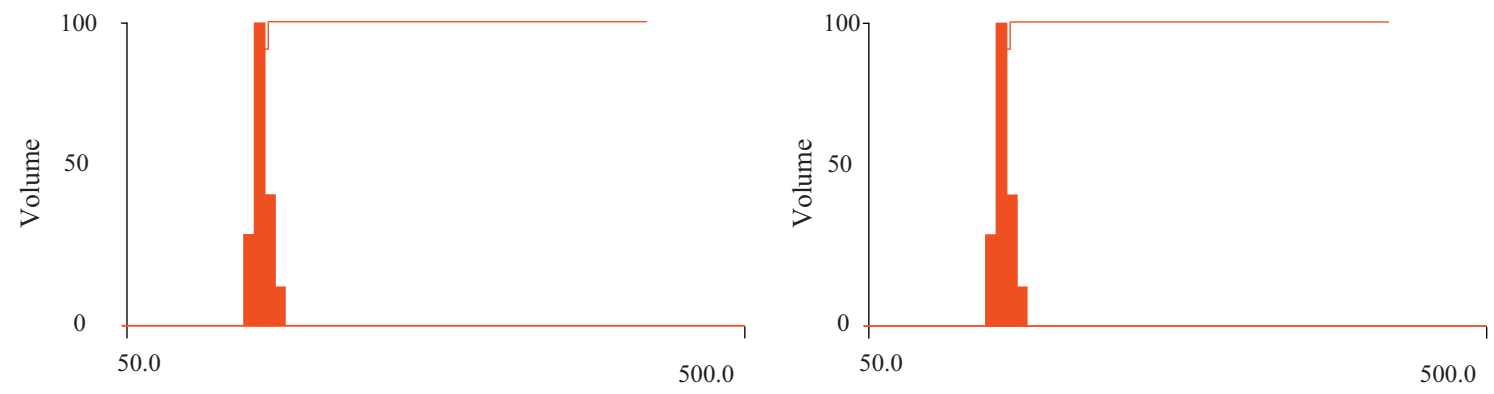

Fig. 4. Particle size distribution of HA solution with the addition of $0.06 \mathrm{mmol} / \mathrm{L}$ alum by using NNLS method.

depended on the structure of the flocs. The mass difference of the cake layer could be overlooked. Nevertheless, if the dosage of $\mathrm{AlCl}_{3}$ is quite low $(0.06 \mathrm{mmol} / \mathrm{L})$, the only thing we can check is to analyze the particle size distribution, especially the smaller fraction. According to the DLS results (Fig. 4), the average particle size of the smaller fraction is $90.8 \mathrm{~nm}$. Apparently, these small particles can enter into the pores and accumulate in channels, causing the pores blockage, and the flux dramatically declined finally.

\subsection{Effects of coagulants on fouling}

Many previous studies suggested that aluminum ion can form complexes with HA $[7,12]$. On the other hand, it also can be absorbed on the surface of colloidal particles, modifies the physicochemical properties of them. In the HA-kaolin synthetic solution, different dosages of aluminum could cause different competition behaviors between HA and kaolin. Fig. 5 presents that aluminum dosage has a great influence on membrane performance in the synthetic solution. Flux decreases by $90 \%$ when the accumulated permeate volume reaches to $125 \mathrm{~mL}$ if $0.06 \mathrm{mmol} / \mathrm{L} \mathrm{AlCl}_{3}$ is added into the synthetic solution. As the dosage of $\mathrm{AlCl}_{3}$ increases to $0.12 \mathrm{mmol} / \mathrm{L}$, the filtration performance is better than that of the other synthetic solutions. However, if the dosage of $\mathrm{AlCl}_{3}$ increases to $0.16 \mathrm{mmol} / \mathrm{L}$, the flux is reduced.

As shows in Table 1 , when $0.06 \mathrm{mmol} / \mathrm{L} \mathrm{AlCl}_{3}$ is added into the synthetic solution, the solution still keeps very stable and no visible flocs are formed. However the removal efficiency of $U_{254}$ can achieve above $90 \%$. In order to find out the reason, DLS is used to analyze the differences of the small size fraction of the particles before and after addition of $0.06 \mathrm{mmol} / \mathrm{L} \mathrm{AlCl}_{3}$ into the synthetic solution. Fig. 6 provides the small size particle profile of HA-kaolin synthetic solutions. Clearly, the average size of $19.1 \mathrm{~nm}$ is much

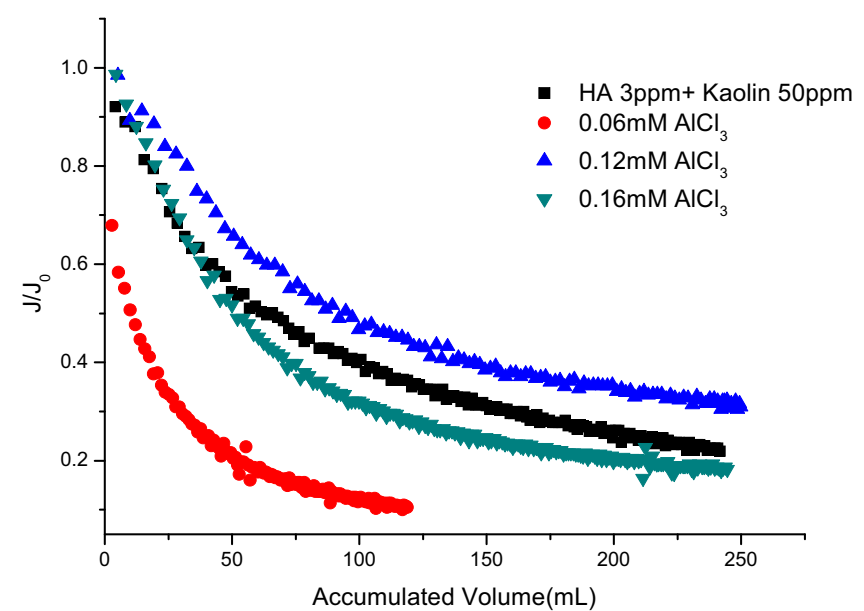

Fig. 5. Flux variations with different dosages of alum in the synthetic water. lower than the membrane size. Therefore, almost all small particles would pass through the MF membrane and exhibited no effect on the flux. When $0.06 \mathrm{mmol} / \mathrm{L} \mathrm{AlCl}_{3}$ is added into the synthetic solution, there are two peaks as indicated in Fig. 6 . One is $50 \mathrm{~nm}$ and another is $500 \mathrm{~nm}$ with an average size of $295 \mathrm{~nm}$. This increased average size is much closer to the membrane pore size. Although the solution is still stable, the particles can more easily block the membrane surface pores and channels, leading to a sharp increase in filtration resistance and a dramatic reduction in membrane flux. In addition, although aggregation is not observed with the addition of $0.06 \mathrm{mmol} / \mathrm{L} \mathrm{AlCl}_{3}$, it is inevitable that aluminum ion and $\mathrm{HA}$ can interact with each other and form complexes, which can shelter some functional groups in HA molecules and result in decrease of surface potential of HA. And the structure of HA could change from flexible linear shape into twist spherical one, leading to serious pore blocked. Hence it become easier for HA to approach and absorb on the membrane surface or pores, causing rapid decline of flux.

As mentioned above, coagulation displays both positive and negative effects during membrane filtration. Membrane flux deteriorates in the HA-kaolin solution with the dosage of $0.16 \mathrm{mmol} / \mathrm{L}$ $\mathrm{AlCl}_{3}$, compared to that of no aluminum addition, which illustrates coagulation has negative effect on improving membrane flux. By contrast, the flux increases with the dosage of $0.12 \mathrm{mmol} / \mathrm{L}$ aluminum, indicating coagulation appeared positive effect during coagulation-microfiltration membrane process. The results show that structure of the formed flocs has a significant role on coagulation pretreatment [32]. And the dosage of coagulant is a key parameter to decide the effect of coagulation.

The results with different dosage of aluminum are analyzed by using several blocking models developed by different assumptions $[33,34]$ (Table 2), as shows in Fig. 7. It can be easily known that cake filtration model (Fig. 7(d)) has the best linear fitting in all dosages

Table 2

Four typical fouling models.

\begin{tabular}{cll}
\hline Law & Equation & Description \\
\hline $\begin{array}{l}\text { Complete blocking (pore } \\
\text { blocking) }\end{array}$ & $V=\frac{J_{0}}{k_{C B}}\left(1-\mathrm{e}^{-k_{C B} t}\right)$ & $\begin{array}{l}\text { Particles do not accumulate } \\
\text { on each other and particles } \\
\text { arriving at the membrane } \\
\text { will seal pores, } d_{\text {particle }} \approx d_{\text {pore }}\end{array}$ \\
$\begin{array}{c}\text { Intermediate blocking } \\
\text { (long term adsorption) }\end{array}$ & $V=\frac{J_{0}}{k_{I B}} \ln \left(1+k_{I B} t\right)$ & $\begin{array}{l}\text { Particles accumulate on each } \\
\text { other and seal membrane } \\
\text { pores, } d_{\text {particle }} \approx d_{\text {pore }}\end{array}$ \\
Standard blocking (direct \\
adsorption) & $\frac{t}{V}=\frac{1}{J_{0}}+\frac{k_{S B}}{J_{0}} t$ & $\begin{array}{l}\text { Particles deposit on the } \\
\text { internal pore walls, } \\
\text { decreasing the pore } \\
\text { diameter, } d_{\text {particle }} \ll d_{\text {pore }} \\
\text { Particles are retained due to } \\
\text { layer resistance) }\end{array}$ \\
& $\frac{t}{V}=\frac{k_{C F}}{4 J_{0}^{2}} V+\frac{1}{J_{0}}$ & $\begin{array}{l}\text { sieving and form a cake on } \\
\text { the surface, then deposition } \\
\text { occurs on other particles, } \\
\text { finally all membrane area is } \\
\text { blocked, } d_{\text {particle }}>d_{\text {pore }}\end{array}$ \\
\hline
\end{tabular}



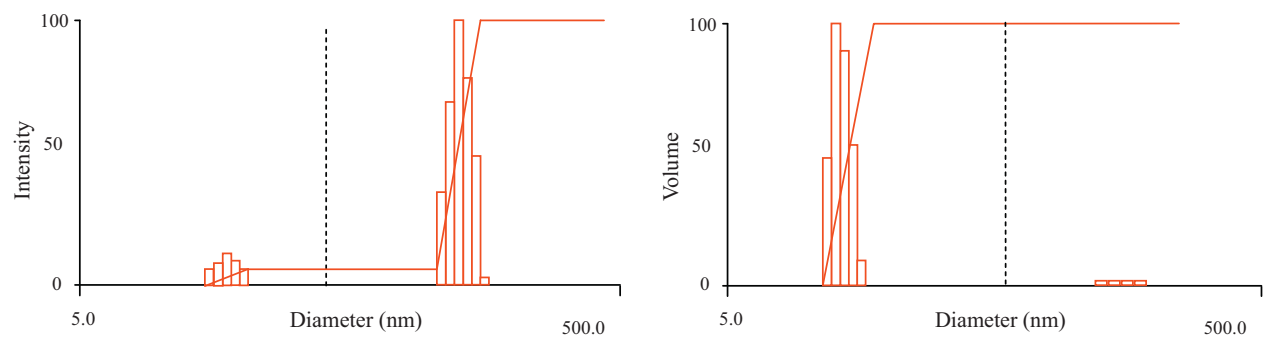

a HA-kaolin system (average particle size $19.1 \mathrm{~nm}$ )
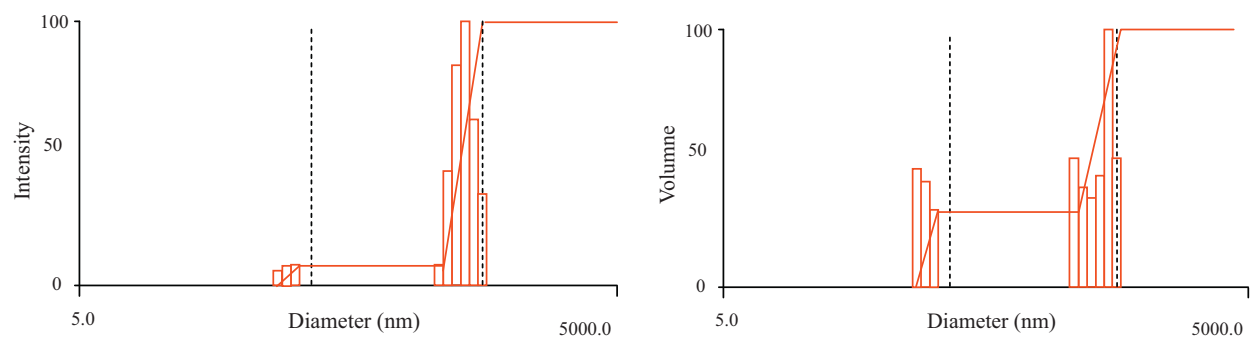

b HA-kaolin system with $0.06 \mathrm{mmol} / \mathrm{L}$ as Al (average particle size $295 \mathrm{~nm}$ )

Fig. 6. Particle size distribution of the HA-kaolin synthetic water by using NNLS method.

(a) Complete Blocking

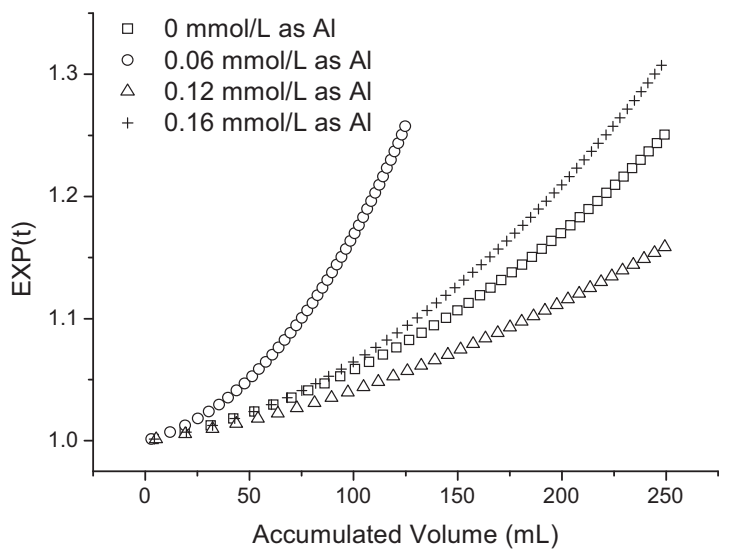

(c) Intermediate Blocking

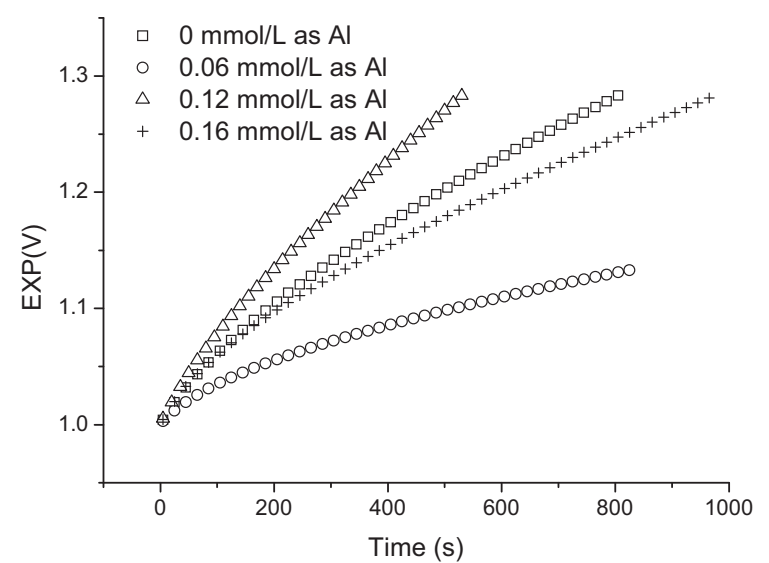

(b) Standard Blocking

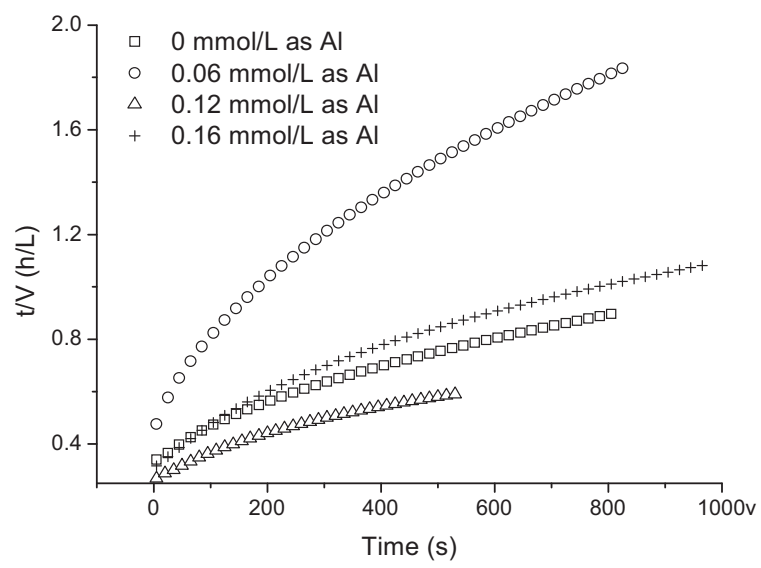

(d) Cake Filtration

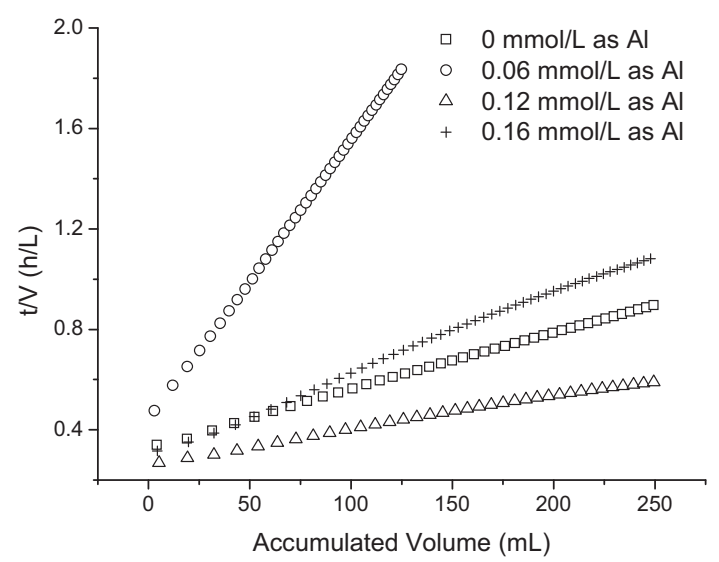

Fig. 7. Mechanisms analysis by using four blocking models under different dosages of alum. 


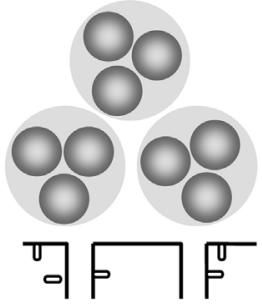

(a)

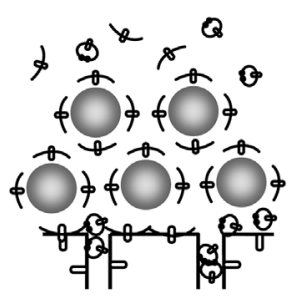

(c)

Kaolin

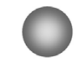

HA

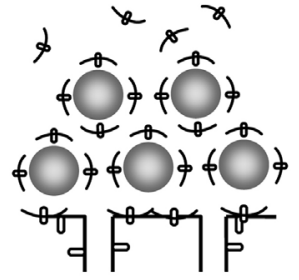

(b)

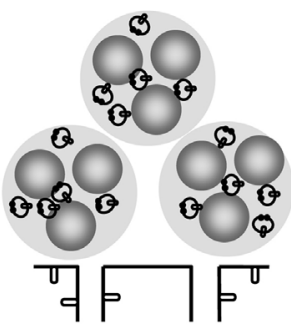

(d)
Aggregate

The complex of HA and Al

Fig. 8. The mechanism of combined fouling of HA and kaolin model solutions with different dosages of aluminum.

of aluminum $\left(R^{2}>0.99\right.$, Table S1). However, other three models display a good linear fitting in various filtration stages $\left(R^{2}>0.95\right)$, indicating that the blocking mechanism is very complicated. In different filtration stage, different fouling processes (Table 2) could take place at the same time. Hence, it is difficult to distinguish these four blocking mechanisms. At present, no uniform model is established and further investigation is required.

Supplementary Table S1 related to this article can be found, in the online version, at http://dx.doi.org/10.1016/j.colsurfa. 2014.07.033.

\subsection{Combined fouling mechanism}

It is generally accepted that HA and FA are the major components of the DOMs in the natural water body $[4,6,7,12]$. The particles, especially the colloidal particles, can react with organic matters through different ways. Adsorption between them is a very common phenomenon. As our synthetic system (HA, $3 \mathrm{mg}$ $\mathrm{C} / \mathrm{L}$, kaolin, $50 \mathrm{mg} / \mathrm{L}$ ), HA is plenty enough to occupy the adsorption sites of the kaolin surface, demonstrates as Fig. 8(b). Compared to the pure kaolin solution (Fig. 8(a)), the repulsion forces between particles are strengthened due to the adsorption of HA. Therefore, the porosity of the cake layer on membrane could be increased a little bit. It can explain why the flux of synthetic solution is better than that of the pure kaolin suspension.

If aluminum is added into the synthetic solution, the situation will become much more complicated. The hydrolysis of aluminum, adsorption of aluminum on colloidal particles and complexation between HA and aluminum will happen at the meantime. The competition of these three reactions is highly relied on the dosage of aluminum. If the dosage of aluminum is low $(0.06 \mathrm{mmol} / \mathrm{L})$, the destabilization and aggregation of the particles will not occur. But the aluminum ion will form the complex with the free HA molecular, which should be prior to the hydrolysis of aluminum and then adsorb on particles. It can be seen from Fig. 8(c), the morphology of HA could be changed from linear structure to the spherical one due to the complexation, resulting in pore blocking and aggravating membrane fouling. Apparently, under this situation, particle size of the complex (formed by HA and almuinum) is quite close to the membrane pore size. Thus, the presence of the kaolin particles has no effect on the membrane performance. With the increase in aluminum dosage, HA will be absorbed by hydrolyzed products of aluminum and the zeta potential would reach more close to zero, which means they will be much more easily to collide with each other and destabilize the kaolin particles, and flocs are formed, then settling down. Additionally, the hydrolysis of aluminum will also take the same effects described in Fig. 8(d). The floc properties can determine the structure of cake layer, such as particle size, intensity and fractal dimension. According to the schematic illustration, it can be explained that if the kaolin particles are in certain extent, the thickness of the cake layer is not as important as the structure of the cake layer, indicating that coagulation may take both positive and negative effects in membrane filtration.

\section{Conclusions}

In this study, the combined effect of HA and kaolin, especially under the addition of aluminum, was investigated during the microfiltration membrane process. The following conclusions can be drawn:

(1) The flux was almost constant for HA solution during the microfiltration experiment due to the linear structure of $\mathrm{HA}$, which made HA easily permeate the membrane. However, the kaolin and synthetic solution displayed a substantial flux decline.

(2) With the low dosage of aluminum as $0.06 \mathrm{mmol} / \mathrm{L}$, there were no visible flocs, but the flux of synthetic solution showed a noticeable decreasing due to the complexation of $\mathrm{HA}$ and aluminum. The morphology of HA could change from linear structure to the spherical one, resulting in pore blocking and aggravating the membrane fouling. With the increase of aluminum content, flocs would be formed, but the filtration performance was apparently improved.

(3) According to the experiments with/without kaolin particles under different dosage of aluminum, the results indicated that the properties of flocs rather than mass of the cake layer were the major determinative factors. Therefore, coagulation may take both positive and negative effects in coagulation-membrane system. The dosage of coagulant was a key parameter to decide the effect of coagulation.

\section{Acknowledgements}

This work was supported by the National Natural Science Foundation of China (Nos. 51008293, 51138008, and 51025830), and Major Science and Technology Program for Water Pollution Control and Treatment (2012ZX07408001-5). The kind suggestions from the anonymous reviewers are highly appreciated.

\section{References}

[1] J.G. Jacangelo, R. Trussell, M. Watson, Role of membrane technology in drinking water treatment in the United States, Desalination 113 (1997) 119-127.

[2] M.R. Wiesner, S. Chellam, The promise of membrane technology, Environ. Sci. Technol. 33 (1999) 360A-366A.

[3] X.Y. Li, H.P. Chu, Membrane bioreactor for the drinking water treatment of polluted surface water supplies, Water Res. 37 (2003) 4781-4791.

[4] H. Huang, K. Schwab, J.G. Jacangelo, Pretreatment for low pressure membrane in water treatment: a review, Environ. Sci. Technol. 43 (2009) 3011-3019.

[5] K. Kimura, N. Yamato, H. Yamamura, Y. Watanabe, Membrane fouling in pilotscale membrane bioreactors (MBRs) treatment municipal wastewater, Environ. Sci. Technol. 39 (2005) 6293-6299. 
[6] K.Y. Choi, B.A. Dempsey, In-line coagulation with low-pressure membrane filtration, Water Res. 38 (2004) 4271-4281.

[7] M. Dong, B.Y. Gao, W.Y. Xu, Y. Wang, R.R. Mao, Effect of calcium on floc properties and membrane foulings in coagulation-ultrafiltration process by polyaluminiuminum chloride $(\mathrm{PACl})$ of different $\mathrm{OH} / \mathrm{Al}^{3+}$ values, Desalination 294 (2012) 30-35.

[8] P. Xiao, F. Xiao, D.S. Wang, T. Qin, S.P. He, Investigation of organic foulants behavior on hollow-fiber UF membranes in a drinking water treatment plant, Sep. Purif. Technol. 95 (2012) 109-117.

[9] V. Lahoussine-Turcaud, M.R. Wiesner, J.Y. Bottero, Fouling in tangential-flow ultrafiltration: the effect of colloid size and coagulation pretreatment, J. Membr. Sci. 52 (1990) 173-190.

[10] A.W. Zularisam, A.F. Ismail, R. Salim, Behaviors of natural organic matter in membrane filtration for surface water treatment - a review, Desalination 194 (2006) 211-231.

[11] A.Y. Lee, J. Cho, M. Elimelech, Combined influence of natural organic matter (NOM) and colloidal particles on nanofiltration membrane fouling, J. Membr. Sci 262 (2005) 27-41.

[12] Y. Wei, A.L. Zydney, Humic acid fouling during ultrafiltration, Environ. Sci. Technol. 34 (2000) 5043-5050.

[13] A.R. Costa, M.N. Pinho, Effect of membrane pore size and solution chemistry on the ultrafiltration of humic substances solutions, J. Membr. Sci. 255 (2005) 49-56.

[14] T. Thorsen, Membrane filtration of humic substances - state of the art, Water Sci. Technol. 40 (1999) 105-112.

[15] K.J. Wilkinson, A. Joz-Roland, J. Buffle, Different roles of pedogenic fulvic acids and aquagenic biopolymers on colloid aggregation and stability in freshwaters, Limnol. Oceanogr. 42 (1997) 1714-1724.

[16] C.R. O'Melia, C.L. Tiller, Physicochemical aggregation and deposition in aquatic environments, Environ. Part. Boca Raton 2 (1993).

[17] W. Stumm, J. Morgan, Aquatic Chemistry, third ed., Wiley-Interscience, New York, 1995.

[18] D. Jermann, W. Pronk, M. Boller, Mutual Influences between natural organic matter and inorganic particles and their combined effect on ultrafiltration membrane fouling, Environ. Sci. Technol. 42 (2008) 9129-9136.

[19] R. Fabris, E.K. Lee, C.W.K. Chow, V. Chen, M. Drikas, Pre-treatments to reduce fouling of low pressure micro-filtration (MF) membranes, J. Membr. Sci. 289 (2007) 231-240.
[20] A.T. Pikkarainen, S.J. Judd, J. Jokela, L. Gillberg, Pre-coagulation for microfiltration of an upland surface water, Water Res. 38 (2004) 455-465.

[21] X. Zheng, S. Plume, M. Ernst, J.P. Croué, J. Martin, In-line coagulation prior to UF of treated domestic wastewater-foulants removal, fouling control and phosphorus removal, J. Membr. Sci. 403-404 (2012) 129-139.

[22] S.H. Kim, S.H. Moon, C.H. Yoon, S.K. Yim, J.W. Cho, Role of coagulation in membrane filtration of wastewater for reuse, Desalination 173 (2005) 301-307.

[23] J. Wang, J. Guan, S.R. Wong, T.D. Waite, Effect of aggregate characteristics under different coagulation mechanisms on microfiltration membrane fouling, Desalination 258 (2010) 19-27.

[24] T. Carroll, S. King, S.R. Gray, B.A. Boltom, N.A. Booker, The fouling of microfiltration membranes by NOM after coagulation treatment, Water Res. 34 (2000) 2861-2868.

[25] A.I. Schafer, A.G. Fane, T.D. Waite, Cost factors and chemical pretreatment effects in the membrane filtration of waters containing natural organic matter, Water Res. 35 (2001) 1509-1517.

[26] S.J. Judd, P. Hillis, Optimisation of combined coagulation and microfiltration for water treatment, Water Res. 35 (2001) 2895-2904.

[27] G. Best, M. Singh, D. Mourato, Y.J. Chang, Application of immersed ultrafiltration membranes for organic removal and disinfection by-product reduction, Water Sci. Technol: Water Supply 1 (2001) 221-231.

[28] A.E. Contreras, A. Kim, Q.L. Li, Combined fouling of nanofiltration membranes: mechanisms and effect of organic matter, J. Membr. Sci. 327 (2009) 87-95.

[29] M.C. Law, X.Y. Li, Q.L. Li, The combined colloid-organic fouling on nanofiltration membrane for wastewater treatment and reuse, Sep. Sci. Technol. 45 (2010) 935-994.

[30] K. Ghosh, M. Schnitzer, Macromolecular structures of humic substances, Soil Sci. 129 (1980) 266-276.

[31] M.J. Avena, A.W.P. Vermeer, L.K. Koopal, Volume and structure of humic acids studied by viscometry: $\mathrm{pH}$ and electrolyte concentration effects, Colloid Surf. A 151 (1999) 213-224.

[32] B.Q. Zhao, D.S. Wang, T. Li, C.W.K. Chow, C.P. Huang, Influence of floc structure on coagulation-microfiltration performance: effect of Al speciation characteristics of PACls, Sep. Purif. Technol. 72 (2010) 22-27.

[33] J. Hermia, Constant pressure blocking filtration laws - application to power-law non-Newtonian fluids, Chem. Eng. Res. Des. 60 (1982) 183-187.

[34] G. Belfort, R.H. Davis, A.L. Zydney, The behavior of suspensions and macromolecular solutions in crossflow microfiltration, J. Membr. Sci. 96 (1994) 1-58. 